"The instrument $I$ use is an ordinary couching needle, with a double cutting edge, as in the operation for solution-the needle being introduced as before described, when speaking of couching and solution. I first endeavour to cut up as much of the lens in situ, without dislocating it from its natural position, as possible. If the cataract be of the softer kind, it of course yields to the needle, and the operation then becomes simply that by solution; if it be so hard that it cannot be cut up, the capsule, at least, is freely lacerated, and then the point of the needle being raised, is made very gently to press the lens downwards, to the extent of a few lines only, and just sufficient to admit of the entrance of a few rays of light. It rarely happens, however, that the cataract is so uniformly hard, but that some portion of it, at least, may be cut ap. The lens being held in this position for a few seconds, the needle is then carefully withdrawn."-p. 233.

This procedure, which consists of a mixture of the operations for solution and depression, does not appear to us to be altogether free from objection. In the first place, if the cataract is to be got rid of by solution, that will be accomplished just as readily by the admission of the aqueous humour through a free laceration in the capsule, the lens being left in situ, as by any superadded attempt at depressing it. And, secondly, if the cataract is to be removed out of the axis of vision, it will be better to do that effectually, than to depress it for a few lines only, and thus, if it be of such a kind as not to admit of absorption, to enable the patient merely to see over its upper edge. We are of opinion that, putting out of consideration the difference in skill in different operations, the kind of operation that should be performed depends upon the nature of the cataract, and the sort of eye which is to be dealt with. Upon the whole, we do not think that the author has given sufficient evidence in proof of the superiority of his operation over the older ones of extraction, reclination, or solution.

Taken as a whole, the work is interesting, as containing the results of the author's experience, which appears to have been unusually great. We cannot, however, recommend it, as a manual of ophthalmic surgery, to the student or practitioner, as it is defective in several most important points, no mention being made of some diseases, such as choroiditis, retinitis, \&c., while others are discussed in a somewhat cursory and superficial manner. The treatment, also, recommended by the author, appears to us to be far too inactive for general adoption in this country, however useful it may have been in the relaxed and debilitated constitutions of the inhabitants of India.

ROTAL MEDICAL AND CHIRURGICAL SOCIETY. Tuesday, December 10, 1844

E. STANLEY, F.R.S. PRESIDEN'T.

OBSERVATIONS ON CLEFT PALATE AND ON STAPHYLORAPHY By Wm. Fergusson, Esq., Professor of Surgery in King's College, London.

The author commences his paper by making some general remarks on the operations for cleft palate, performed in this country and abroad. He then proceeds to give a detailed account of a dissection which he had the opportunity of making of the muscles which operate upon the soft palate, in an individual who had both the velum and a portion of the hard palate cleft. This description is followed by an examination of the opinions of different eminent physiologists concerning the motions of the velum palati and its arches during the acts of deglutition, and by the author stating his own views as to the actions of the various muscles when the palate is eleft. This part of the subject he further illustrates, by describing four different states in which the flaps on each side may be seen upon looking into the mouth of a person who has a split palate, and irritating them in different ways. By pursuing this course of anatomical and physiological inquiry, he arrives at the following conclusions:-1. That the flaps are slightly drawn upwards and to the sides, where the levator palati contracts. 2. That when the levator palati and palato pharyngeus act strongly and together, the flaps are so forcibly drawn from the mesial gap, that they can scarcely be distinguished from the sides of the pharynx. 3. That the flaps are forced together, and the edges come into contact, when the superior constrictor muscle contracts, during the act of deglutition. 4. That the circumflexus palati possesses but a feeble power over the flaps. Lastly, the fibres of the palato-glossus were very imperfectly developed in the specimen in his possession. The chief object of his paper is to communicate a novel plan of operating in staphyloraphy, founded on the above investigations, and which he has put in practice, with most flattering results, in two cases, during the last twelve months. The principle of his new proposal is to divide those muscles of the palate which have the effect of drawing the flaps from each other, and widening the gap between them, when they contract, so that the stretched velum may be in a state of repose, and the pared edges may not be pulled asunder by any convulsive action of the parts during the process of union. In other words, he advises, as an important accessory to the operation of staphyloraphy, the division of the levator palati and palato-pharyngeus muscles, and, if requisite, the palato-glossus. In bringing forward this plan he reviews the different modes of operating which have been pur. sued by numerous distinguished surgeons who have written on the subject; and concludes, by entering into several minute details regarding the steps in his own operation, and by describing the particular forms of instruments which he has found best adapted for his proceedings. The preparation of cleft palate, a dissection of the parts in the usual condition of the throat, a variety of diagrams, instruments, \&c., were on the table, to illustrate the views of the author.

Mr. STANrey called the attention of the society to the anatomy of the cleft palate, as described by the author, who, he was sure, would be anxious to know whether any gentleman present had ever dissected the parts in that condition, and what observa. tions he had made on the subject.

Mr. Cessar Hawnins wished to know the age of the patients upon whom Mr. Fergusson had operated, and whether in these cases the fissure involved the hard palate as well as the soft.

Mr. Fergusson answered, that he had acted in those cases in accordance with a rule which had been universally agreed upon amons practical surgeons-viz., that the patients should be of an adult age, and the parties alluded to had been so. In neither instance had the fissure involved much of the hard parts, nor did he think that such a condition made much difference as regarded the operation which he proposed, for, as stated in his paper, the soft tissues alone were under the influence of the motor powers which he had pointed out; and in the event of an operation similar to that followed by Warren, it was evident that there was no motory influence likely to affect the tissues dissected from the bones. There were some casts on the table exhibiting the condition of the cleft in the hard palate, and it would be apparent, on examining them, that the soft tissues, if dissected, and brought downwards, would meet in the mesial line with great facility.

Mr. STANLEx remarked, that the explanation given by the author of the paper of the manner in which persons affected with cleft palate were enabled to swallow food without its passing upwards into the nostrils, and the recommendation to divide the muscles, which were described as moving the palate, constituted the principal novelties put forth, and were highly deserving of consideration. He should wish to hear some observation on these subjects; or were the novelties such that the members were not prepared to discuss them?

Sir GEORGE LEFEVRE regretted to find a paper of such magnitude likely to be passed by without eliciting any observations. He would ask Mr. Fergusson how long it was after the operation before the fissure was perfectly closed, and what was the effect on the power of speech? He expressed his opinion that a paper of greater importance and interest had not been read before the society for a long time, and trusted that the discussion would not be suddenly closed.

Mr. Fergusson, in answer to the queries of Sir George Lefevre, noticed that he had referred to the cases on which he had operated, more with the purpose of shewing that he had some proof on the living body in testimony of the correctness of his views, than for the purpose of detailing particulars; but as Sir George had questioned him on the subject, he should be happy to give a brief history of the two examples in which he had performed the operation. The first case was that of a young gentleman, seventeen years of age, who suffered under this congenital defect. He had arrived at that period of life when he felt anxious to do something for himself, and as his interest lay with the army, he had prospects of a commission, but felt conscious that his chance was very indifferent unless something could be done to improve the tone of his voice and articulation. When he was first consulted about the case, the gap appeared so large that he had not been over sanguine as to the success of the operation, in so far as regarded union; and as to the tone of voiee, he could only hold out hopes that it would be improved, for the ex- 
perience he had himself, with reference to the voice, was not such as to incline him to say much on the subject.

The young gentleman was willing to submit to any operation which should give a chance of improvement, and accordingly a proceeding had been followed, such as that deseribed in the paper. Unfortunately, a part of the gap had opened again; but some months after, the patient cheerfully submitted to another operation, which had been attended with complete success.

$\mathrm{He}$ well remembered what attention he had hestowed to the first sounds which the patient was permitted to make. $\mathrm{He}$ observed a decided improvement, yet, on the whole, when the patient was allowed to use his roice freely, he had been disappointed; the tones and mode of articulation remained much the same as before the operations, and continued so until the party placed himself under a teacher of elocution. About eight months after the operation, this patient went under the tuition of a gentleman well linown to the profession and the public for the wonderful changes he had effected on the voice and articulation-Mir. Hunt,- - under whose instructions the improvement had, in a short time, been amazing ; so much so, indeed, that he (Mr. F.) had no doubt that the patient would be deemed eligible for the profession to which he aspired; and he imagined, also, that when this young man returned among his friends, their astonishment would be equal to that expressed by the friends of Mr. Stephenson, the party on whom the operation was first successfully performed by Roux, when they heard his voice, on his appearance among them.

The other case was that of a young lady, also about seventeen years of age, who was so conscious of her great defect, that she seldom attempted to speak, preferring to remain silent when in company. She was willing to submit to any operation which should offer any chance of improvement. The proceeding had been successful in her case. He thought that it would be improper not to mention, that although he had stated, in the paper, that union had been complete, there still remained, in this instance, a small aperture in front, which, however, he had no doubt, would be closed by and by. It must be known to those who are familiar with the histories of these operations, that they occasionally have to be repeated, and that apertures remain for some time after, until closed by the use of caustic or cautery. In this example, it might be said that the patient still required to learn to speak; and he imagined, that if placed under an able teacher of elocution, she would soon be able to articulate with facility. As regarded the tone of voice, he could not from his own experience say much, but had questioned both Drs. Mütter and Warren, when they were in this country, last summer, on the subject, and he had learnt from them, that they had reason to be disappointed in some instances. It was easy to tell, in the first few days, whether the union was likely to be successful In three, four, six, or ten days, the stitches were removed, and if the parts then kept together, there was nothing further to apprehend.

Whilst on these subjects, he wonld refer to the history of a case lately told to him by Sir Benjamin Brodie. Sir Beniamin had operated successfully on a young gentleman of high connexions, but his power of speech was in no degree improved, matil he had taken lessons in elocution, when the change was so great, that the party soon after obtained a commission in the army.

Dr. GREGORY inquired whether in either of the cases mechanical means had been tried, prior to the performance of the opera. tion, and whether they had produced any result; if so, of what nature? He should also be glad to know from Mr. Fergusson the results of his experience of mechanical applications in such cases.

Mr. Partridge wished to ask Mr. Fergusson whether there existed any difficulty in the elevation of the soft palate after these operations, and whether there seemed any difficulty of deglutition afterwards?

Mr. Fergusson, in answer to Dr. Gregory's questions, stated that no mechanical means had been adopted in either of the cases alluded to, and he himself had no experience regarding artificial palates. He believed, however, that there were gentlemen in the room well qualified to give their opinions on such matters. $\mathrm{Mr}$. Partridge's question, he (Mr. Fergusson) imagined led to a wide field of controversy, for he found that the highest authorities differed in opinion as to the action and condition of the soft velum during deglutition. For his own part, he imagined that there was but little movement in it at that period. He could say, however, that in one of his patients-the case which had been longest under his notice - the movements seemed much the same as in the natural palate. He felt satisfied that he could observe the action of the levator palati, just as in the well-formed parts. This sub ect was alluded to in the paper, and he had no doubt that the levator palati had formed new adhesions to the velum. It was worthy of remark, that during the early attempts at deglutition after the operation, the fluid, or bolus, was slipped backwards with great gentleness. The tender state of the parts, as well as the caution of the surgeon, put the patient on his guard on such occasions. At first, too, the soft velum was so indurated and thickened that the patient could use little freedom with it, but in the course of time it assumed more of a natural condition, and then both deglutition and speech were much facilitated.

Mr. Snaw remarked that Mr. Fergusson's not laying much stress upon the action of the circumflexus, or tensor palati, might by some be deemed a weak point in the paper, as it might be supposed that if it were not divided, its action might tend to separate the lips of the wound. After some reflection on the subject, he himself was not inclined to attach much importance to its effect on the soft parts, but would be glad to learn Mr. Fergusson's opinion on the subject.

Mr. Fergusson stated that he had mentioned in his paper his opinion that this muscle had but little control over the moveable parts. He had at one time supposed that it had considerable influence, but on a careful examination, both in the preparation referred to, and in the natural state of the parts, he felt satisfied that the power of the muscle was not at all likely to interfere with the result of an operation. The shape, development, and course of the muscle were all such as to convince him on this point, and he referred, in corroboration of his views, to a dissection of the healthy parts on the table in the room. The word tensor, perhaps, implied, in the estimation of some, a greater power than the muscle in question really possessed. The motion was scarcely more than perceptible; it was a mere act of tension.

Mr. Partridge inquired whether the circumflexus, or tensor palati, was not remarkably small in the preparation which had been exhibited?

Mr. Fergusson replied that he did not think so; in fact, it appeared to him that the muscle was in reality larger than in the natural condition, and also that the action was in some degree more apparent in the specimen of cleft palate, than where the velum was entire.

In answer to a question by Mr. Henry Chardes Johnson as to the regurgitation of food into the nostrils, after the operation, Mr. Fergusson explained that the partition made by the operation seemed to have the effect of completely preventing the escape upwards of all articles of food and drink.

The next meeting of the society will be held on Tuesday, the 14th of January, 1845.

\section{CHEMICAL SOCIETY.}

Monday, December 2, 1844.

R. PORRETT, ESQ. IN THE CHAIR.

Tre first paper read this evening was by Dr. JoHN STENHouse "On a Test for Genuine Quina Barks." This test is intended to detect the presence of kinic acid, which distinguishes the true from the spurious barks of commerce. A quarter of an ounce of the bark, to be tested, is boiled for some time, with the addition of an excess of caustic lime, the decoction strained, and placed in a retort, with sulphuric acid and peroxide of manganese. Upon being distilled over, the presence of chinon in the retort denotes the presence of kinic acid in the bark experimented upon, and consequently those alkaloids associated with it which render the bark valnable. Traces of kinic acid exist in willow and other indigenous barks, but two to three ounces of bark must be operated upon to detect it.

The second paper was by Dr. Hoffman, on Chloramil, a subject of great interest to organic chemistry, to which we shall

Other papers, of no great interest, were read; but one by Dr. Bence Jones destrves notice, its object being to shew that when urine and other saline fluids in which free ammonia exists, are tested with litmus paper, the primary reaction is alkaline, but upon drying the paper in the open air, it becomes invariably reddened, as if from the presence of a free acid. This curious fact depends upon the evaporation of ammonia, which proceeds just so far as to leave an acid salt.

Monday, December 16.

A. AIKEN, ESQ. IN THE CHAIR.

"On some kinds of Green Glass of Commerce," by Robent WARrington, Esq. of A pothecaries' Hall. Some green glass bottles having been submitted to Mr. Warrington for examination, which, it was alleged, had imparted a bad flavour to the wine contained in them, they were found to have the inner surface rough and opaque, and to be readily acted upon by tartaric acid. A comparative analysis of the glass of these bottles with 